\title{
Prenatal undernutrition and postnatal overnutrition alter thyroid hormone axis function in sheep
}

\author{
L Johnsen, A H Kongsted and M O Nielsen
}

Department of Veterinary Clinical and Animal Sciences, Faculty of Health and Medical Sciences, University of Copenhagen, Groennegaardsvej 7, DK-1870 Frederiksberg, Denmark

Correspondence should be addressed to M O Nielsen

Email

mette.olaf.nielsen@sund.ku.dk

\begin{abstract}
Mounting evidence led us to hypothesize that i) function of the thyroid hormone (TH) axis can be programed by late gestation undernutrition (LG-UN) and ii) early-postnatal-life overnutrition (EL-ON) exacerbates the fetal impacts on TH axis function. In a $2 \times 2$ factorial experiment, 21 twin-bearing sheep were fed one of two diets during late gestation: NORM (fulfilling energy and protein requirements) or LOW (50\% of NORM). From day 3 to 6 months after birth (around puberty), the twin lambs were assigned to each their diet: conventional (CONV) or high-carbohydrate, high-fat, where after half the lambs were killed. Remaining sheep (exclusively females) were fed the same moderate diet until 2 years of age (young adults). At 6 months and 2 years of age, fasting challenges were conducted and target tissues were collected at autopsy. LG-UN caused adult hyperthyroidism associated with increased thyroid expression of genes regulating $\mathrm{TH}$ synthesis and deiodination. In one or more of the target tissues, liver, cardiac muscle, and longissimus dorsi muscle, gene expressions were increased by LG-UN for TH receptors (THRA and THRB) and deiodinases but were decreased in visceral and subcutaneous adipose tissues. EL-ON increased TH levels in adolescent lambs, but this was reversed after diet correction and not evident in adulthood. We conclude that LG-UN programed TH axis function at the secretory level and differentially in target tissues, which was increasingly manifested with age. Differential TH signaling in adipose vs other tissues may be part of a mechanism whereby fetal malnutrition can predispose for obesity and other metabolic disorders.
\end{abstract}

\section{Key Words}

- Development
.

(

.

(
- thyroid hormone metabolism
- nutrition

Journal of Endocrinology (2013) 216, 389-402

\section{Introduction}

It has become increasingly clear from both epidemiological (Phillips et al. 1998, Laitinen et al. 2004, Rich-Edwards et al. 2005) and experimental animal studies (Woodall et al. 1996, Ozanne et al. 2003, Bol et al. 2009) conducted over the last 20 years that malnutrition during fetal life may predispose for adverse health outcomes later in life, including obesity, type 2 diabetes (T2D), and cardiovascular disease (CVD). The phenomenon associating adverse exposures during fetal life with altered body functions and health outcomes later in life is often referred to as fetal metabolic programing (FMP). Experience from developing countries undergoing rapid economic transition indicates that individuals who have been adversely programed during fetal life have an increased risk of developing these diseases when exposed to a mismatching overnutrition situation later in life. In certain developing 
countries, the incidence of intrauterine growth restriction may be as high as $50 \%$ and evidence suggest that as income levels rise, obesity, T2D, and CVD become more prevalent among children and young adults (Amuna \& Zotor 2008). It is therefore important to get deeper insight into the (molecular) biological mechanisms underlying fetal programing in order to develop targeted and efficient intervention strategies to prevent or reverse later adverse health outcomes. The major endocrine systems in focus in research relating to fetal programing have been the hypothalamic-pituitary-adrenal axis function and the glucose-insulin axis including pancreatic endocrine function and the development of insulin resistance (Bloomfield et al. 2004, Ozanne et al. 2005, Limesand et al. 2006). Only a few studies have addressed the implication of fetal malnutrition for hypothalamicpituitary-thyroid function later in life and results have been contradictory as presented in the following.

Thyroid hormones (THs) are required for normal function and development of nearly all tissues and regulate oxygen consumption and overall metabolic rate. THs increase RNA synthesis of target genes and increase mitochondrial oxidation. There are reports of altered thyroid function associated with both development of the metabolic syndrome and a history of fetal growth restriction. In patients with the metabolic syndrome, obesity, and insulin resistance have been found to stimulate thyroid cell proliferation and increase thyroid volume and stimulate the production of THs (Sari et al. 2003, Pergola et al. 2008, Rezzonico et al. 2008, Ayturk et al. 2009). In a birth cohort study, Kajantie et al. (2006) found that a small body size at birth and during childhood increases the risk of spontaneous hypothyroidism in adult women, whereas Brix et al. (2000) found, in a populationbased twin case-control study, that low birth weight is not associated with thyroid autoimmunity or nonautoimmune thyroid disease. Thyroid gland metabolism has been shown to be downregulated in both nutrientrestricted suckling rats (Bonomo et al. 2008, Lisboa et al. 2010) and in fetal growth-restricted lambs (Rae et al. 2002); in the rat study by Lisboa et al. (2010), thyroid gland metabolism remained downregulated into adulthood. Others (Dutra et al. 2003, Lisboa et al. 2008) have reported that neonatal protein and energy restriction in suckling rats led to adult hyperthyroidism and increased liver deiodinase activity. However, long-term effects of fetal exposures on thyroid function in other species than the rat have not been thoroughly established and the interactive effects of fetal undernutrition followed by postnatal overnutrition has to our knowledge never been examined in any species.

In this study, we aimed to test the hypothesis that function of the $\mathrm{TH}$ axis is a target of fetal programing induced by late gestation undernutrition (LG-UN) that contributes to predispose for adverse health outcomes later in life. Bearing in mind that postnatal overnutrition has been reported to exacerbate the adverse negative outcomes of FMP, we further hypothesized that earlypostnatal-life overnutrition (EL-ON) will exacerbate the consequences of fetal programing on the TH axis function.

We chose our recently developed Copenhagen sheep model (Nielsen et al. 2012) as an experimental animal model for this study since the late gestation period was in focus, where the major quantitative fetal growth takes place. As discussed by Nielsen et al. (2012), sheep are more comparable to humans in terms of physiological maturity at birth than rodent offspring. In humans and sheep, thyroid formation occurs during the first trimester and the final maturation (primarily increase in thyroid epithelia) during the last trimester before birth (Bocian-Sobkowska et al. 1997, Hájovska 2002, Kratzsch \& Pulzer 2008). In rodents, the hypothalamic-pituitary-thyroidal axis continues to develop simultaneously into the post partum period and is not concluded until 3-4 weeks after birth independent of intrauterine-placental influences (Dussault \& Labrie 1975).

In the Copenhagen sheep model, twin-pregnant sheep were subjected to $50 \%$ energy and protein restriction during the last trimester and twin lambs were raised on a special high-carbohydrate, high-fat (HCHF) diet from 3 days to 6 months of age. We have previously shown in this model that exposure to LG-UN can predispose for increased appetite for a high-fat diet early in postnatal life and predispose for visceral obesity by altering fat deposition patterns (Nielsen et al. 2012), and in this study, we aimed to relate these phenotypic changes to serum TH levels and TH signaling in major target tissues. Serum levels of total tri-iodothyronine $\left(\mathrm{TT}_{3}\right)$ and total thyroxine $\left(\mathrm{TT}_{4}\right)$ were therefore measured at different time points in postnatal life in growing lambs and young adult sheep with different nutritional histories in late prenatal and early postnatal life. Tissue samples were obtained from subgroups of animals killed at 6 months and 2 years of age. Gene expression in the thyroid gland was determined for key targets implicated in the regulation of TH synthesis and release (TSH receptor (TSHR), thyroglobulin (TG), thyroid peroxidase (TPO), solute carrier family 5 (sodium iodide symporter), member 5 (SLC5A5), type II iodothyronine deiodinase (DIO2), and iodotyrosine deiodinase

Published by Bioscientifica Ltd. 
$(I Y D))$. In addition, expression of genes encoding for targets involved in TH signaling (TH receptor $\alpha$ (THRA), $T H R B$, and DIO2) was determined in the major target tissues liver, heart, two skeletal muscles, and two adipose. $I Y D$ expression was also determined in liver.

\section{Materials and methods}

\section{Experimental animals and experimental design}

The Copenhagen sheep model used in this project has been described in detail by Nielsen et al. (2012). All experimental animal handling and procedures were approved by The Danish National Committee on Animal Experimentation. In summary, the experiment was a $2 \times 2$ factorial design with two prenatal and two postnatal nutritional treatments (Fig. 1). Twin-pregnant ewes (Shropshire breed; $n=21$ ) were during the final 6 weeks of gestation (term $=147$ days) fed diets meeting either $100 \%$ (NORM, $n=10$ ) or $50 \%$ (LOW, $n=11$ ) of the daily requirements for energy and protein. The twin lambs were assigned to each their postnatal treatment and individually fed a conventional (CONV) or an obesogenic HCHF diet from day 3 to 6 months post partum, resulting in four treatment groups: NORM:CONV $(n=10)$, NORM:HCHF $(n=10)$, LOW:CONV $(n=11)$, and LOW:HCHF $(n=11)$. The CONV treatment consisted of good-quality artificially dried hay, which was supplemented with a commercial milk replacer until weaning at 56 days of age and daily allowance was adjusted weekly to achieve moderate weight gains of $\sim 225 \mathrm{~g}$ /day. The HCHF diet consisted of dairy cream (38\% fat; with a maximal daily allowance of 0.5 l/day), high-starch popped maize (maximal daily allowance of $1.0 \mathrm{~kg} /$ day), and commercial milk replacer (maximal daily allowance was 2.01 /day until 56 days of age and 0.51 /day thereafter). All animals had free access to water and a vitamin-mineral mix. At 6 months of age (around puberty), half of the animals from each treatment group were killed, which included all males and three females. Only female offspring (a total of 18) continued in the experiment after 6 months of age and they were fed the same moderate grass-based diet until the age of 2 years (young adults), where they were subjected to a fasting challenge and then killed. After killing, thyroids and target organs were quickly excised and weighed and tissue samples were snap-frozen for later RNA extraction. Target tissues included liver (left lobe), two different skeletal muscles (the longissimus dorsi dominated by glycolytic type II fibers and biceps femoris dominated by oxidative type I fibers; Jørgensen et al. (2009), cardiac muscle

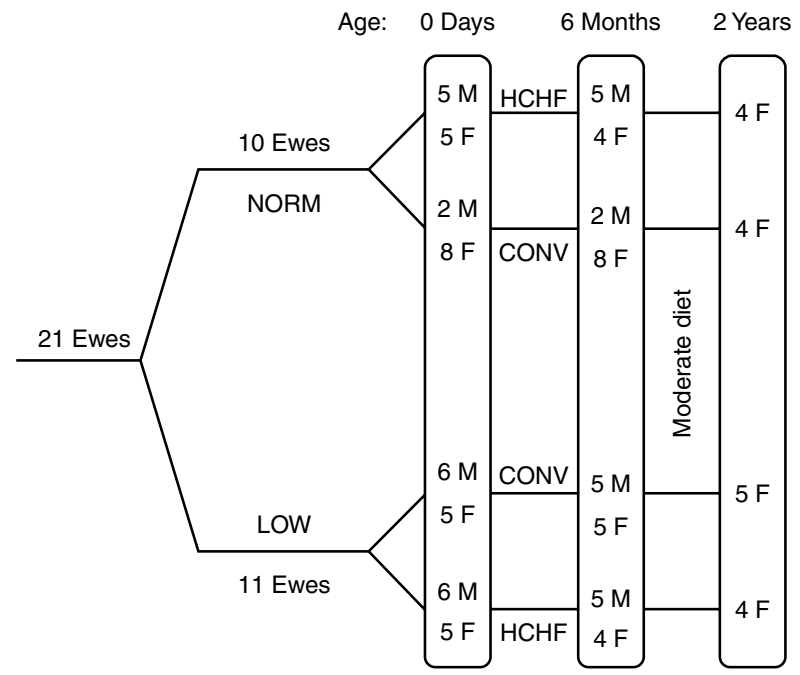

Figure 1

Study design as previously reported in detail by Nielsen et al. (2012). Twin-pregnant ewes were exposed to diets fulfilling $100 \%$ (NORM) or $50 \%$ (LOW) of energy and protein requirements during the last 6 weeks of gestation (term $=147$ days). Twin offspring were assigned to each their experimental diet from 3 days to 6 months post partum; a conventional moderate hay-based diet (CONV) adjusted to achieve moderate growth rates of $\sim 225 \mathrm{~g} /$ day or an obesogenic high-carbohydrate, high-fat diet (HCHF) based on maize and a milk-dairy cream mix. All males were killed at 6 months of age. Only female sheep continued in the experiment after that, and from 6 months to 2 years of age, they were fed the same moderate (and for HCHF sheep: body fat correcting) grass/hay-based diet. Animal numbers and sex ( $M$, males; $F$, females) included at different time points are shown.

(central part of ventriculus sinister cordis), and two adipose tissues (visceral and subcutaneous sampled above the central part of longissimus dorsi).

\section{Blood sampling and serum $\mathrm{TT}_{4}$ and $\mathrm{TT}_{3}$ analysis}

Baseline blood samples were drawn from lambs at 1 day, 56 days, and 6 months of age and from female sheep at 1 and 2 years of age. At 2 years of age, catheters were inserted into both jugular veins, as described previously (Husted et al. 2008), and sheep were subsequently subjected to a 3-day period of fasting. Blood was sampled 0, 24, and 48 after the feed was withheld and $1 \mathrm{~h}$ after re-feeding at $72 \mathrm{~h}$ after initiation of the fasting. The sheep had free access to water during the fasting period. Blood was collected in serum tubes and allowed to coagulate at room temperature for $\sim 30 \mathrm{~min}$. Serum was separated by centrifugation at $1800 \times \mathrm{G}_{\mathrm{av}}$ (at $4^{\circ} \mathrm{C}$ for $15 \mathrm{~min}$ ) and subsequently stored at $-20^{\circ} \mathrm{C}$ until analyzed. Serum $\mathrm{TT}_{4}$ and $\mathrm{TT}_{3}$ concentrations were assessed using a human enzyme immunoassay (DRG Diagnostics, Marburg, Germany). Six out of 195 and 9/195

Published by Bioscientifica Ltd. 
samples had an intra-assay variation $>10 \%$ but below $<15 \%$ for $\mathrm{TT}_{3}$ and $\mathrm{TT}_{4}$ respectively. The interassay variation was $20 \%$ for $\mathrm{TT}_{3}$ (the kit supplied control values with a variation of up to $20-30 \%$ for concentrations in the range of $1.30-2.50 \mathrm{ng} / \mathrm{ml}$ ) and $7.5 \%$ for $\mathrm{TT}_{4}$. Samples from a given animal were analyzed within the same assay kit. Excluding the few samples that yielded large variations from statistics did not affect results.

\section{Relative quantification of gene expression}

mRNAs for SLC5A5, IYD, TPO, DIO2, TG, TSHR, THRA, and $T H R B$ were quantified using quantitative reverse transcriptase PCR and procedures were according to manufacturer's guidelines. Total RNA was extracted with TRIzol Reagent (Invitrogen) and 1-bromo-3chloropropane (Sigma-Aldrich) and cleaned up using SV Total RNA Isolation (Promega) from tissue samples from thyroid, liver, heart muscle, longissimus dorsi, biceps femoris, subcutaneous fat, and visceral fat. Total RNA concentrations and sample purity were established with NanoDrop ND-1000 u.v.-Vis Spectrophotometer (Thermo Fisher Scientific, Waltham, MA, USA) and RNA integrity was confirmed by bioanalysis (Agilent 2100 Bioanalyzer; Agilent Technologies, Santa Clara, CA, USA). RT was performed using $0.5-2 \mu$ g (depending on tissue) total RNA with oligo-dT and random hexamer as primers and with MMLV reverse transcriptase (Promega). The cDNA was pooled to make standard curves and calibrator for each plate. Calibrator, samples, and negative controls were performed in triplicate. Standard curves were made using serial dilutions of cDNA $(1: 2,1: 4,1: 8,1: 16,1: 32$, and $1: 64)$ to determine the efficiency of each primer set within the resulting linear regression. Efficiencies of primers were between 1.8 and 2.1 (this equals to an increase between 80 and $110 \%$ of target nucleic acid in each amplification cycle; Table 1) and all coefficients of determination $\geq 0.99$. Primer sequences were derived from ovine or bovine cDNA sequences obtained from the National Center for Biotechnology Information (NCBI) and primer sequences, NCBI accession numbers, and annealing temperatures are listed in Table 1. SYBR Green (SYBR Green master mix; Roche) was used as the fluorophore, and qPCR was performed using the LightCycler 480 System (Roche). Melt curve analysis was conducted on each sample after the final cycle to ensure that a single product was obtained. Peptidylprolyl isomerase B (cyclophilin B; PPIB) was used as reference mRNA for all tissues except for the two adipose tissues where $\beta$-actin $(A C T B)$ was a better match; the identical first-strand cDNA was used for quantification of specific mRNAs of interest to circumvent any between-run variation. Data were analyzed using the advanced relative quantification method provided by LightCycler 480 instrument version 2.0 Software (Roche). The qPCR products were cleaned up by Wizard SV Gel and PCR clean up system (Promega) and sequenced on ABI3130XL (Applied Biosystems) with BigDye terminator v3.1 cycle sequencing

Table 1 Primer sequences and accession numbers for applied genes

\begin{tabular}{|c|c|}
\hline Gene & Primer sequence \\
\hline Cyс B & $\begin{array}{l}\text { F: GATCCAGGGTGGAGATTTCAC } \\
\text { R: GGCCCATAGTGTTTAAGCTTG }\end{array}$ \\
\hline ACTB & $\begin{array}{l}\text { F: ACCCAGATCATGTTCGAGACCTT } \\
\text { R: TCACCGGAGTCCATCACGAT }\end{array}$ \\
\hline SLC5A5 & $\begin{array}{l}\text { L: CGGAATCATCTGCACCTTCT } \\
\text { R: GGACAACCCAGAAACCACTC }\end{array}$ \\
\hline IYD & $\begin{array}{l}\text { L: TTCTCCCACAGTCGATACCC } \\
\text { R: ATCTGGGTCCTTCACAACCA }\end{array}$ \\
\hline DIO2 & $\begin{array}{l}\text { L: GTGGCTGACTTCCTGTTGGT } \\
\text { R: GCATCGGTCTTCCTGGTTC }\end{array}$ \\
\hline TPO & $\begin{array}{l}\text { L: ATCACGGATTCCAACTCCAA } \\
\text { R: GGGTCCACTTCATCCTCACA }\end{array}$ \\
\hline$T G$ & $\begin{array}{l}\text { L: GAGCAGGTTTCCAGAGGTGT } \\
\text { R: AGAGTGGTCTCAGCGAAGGT }\end{array}$ \\
\hline$T S H r$ & $\begin{array}{l}\text { L: GGGAGTGAGGAGATGGTGTG } \\
\text { R: GAGGATGACCAGGACGAAGA }\end{array}$ \\
\hline THRA & $\begin{array}{l}\text { L: CCTCTTCTCTCCTCCCTCTC } \\
\text { R: TTGTCCGCTCTTAGTTCTCC }\end{array}$ \\
\hline$T H R B$ & $\begin{array}{l}\text { L: GAAGCTCGTGGGAATGTCT } \\
\text { R: GCCTTTGCACTTCTTCTCCT }\end{array}$ \\
\hline
\end{tabular}

\begin{tabular}{llll}
\hline NCBI accession no. & $\begin{array}{l}\text { Annealing } \\
\text { temperature }\left({ }^{\circ} \mathrm{C}\right)\end{array}$ & & Efficiency \\
\cline { 1 - 2 } AJ865374 (Oa) & 60 & 1.88 \\
AY141970 (Bt) & 60 & 1.83 \\
XM_581578.5 (Bt) & 60 & 1.87 \\
NM_001102165.1 (Bt) & 60 & 2.19 \\
NM_001010992 (Bt) & 60 & 1.97 \\
XM_603356.5 (Bt) & 60 & 1.91 \\
NM_173883.2 (Bt) & 60 & 2.00 \\
NM_001009410.1 (Oa) & 60 & 1.97 \\
NM_001100919.1 (Oa) & 60 & 1.92 \\
NM_001190391.1 (Oa) & 57 & 2.18 \\
\hline
\end{tabular}


kit and Hi-Di formamide (Applied Biosystems). Sequences were confirmed using the NCBI blast logical alignment search tool.

\section{Statistical analysis}

It should be noted that in the data based on tissue samples obtained at killing, sex differences cannot be distinguished at the two different ages, as no males were killed at 2 years of age and only three females were killed in the 6-month old group (they were all from the NORM-CONV group). Inclusion of gene expression data for these three, 6-month old female NORM-CONV lambs did not impact outcomes of the statistical tests and their data are therefore included in the results presented here. The variable sex is therefore eliminated from the model for data derived from tissue samples in 2-year-old sheep.

For all other data, gender-specific responses to the late gestation and early postnatal life nutrition exposures could be evaluated for growing lambs up to 6 months of
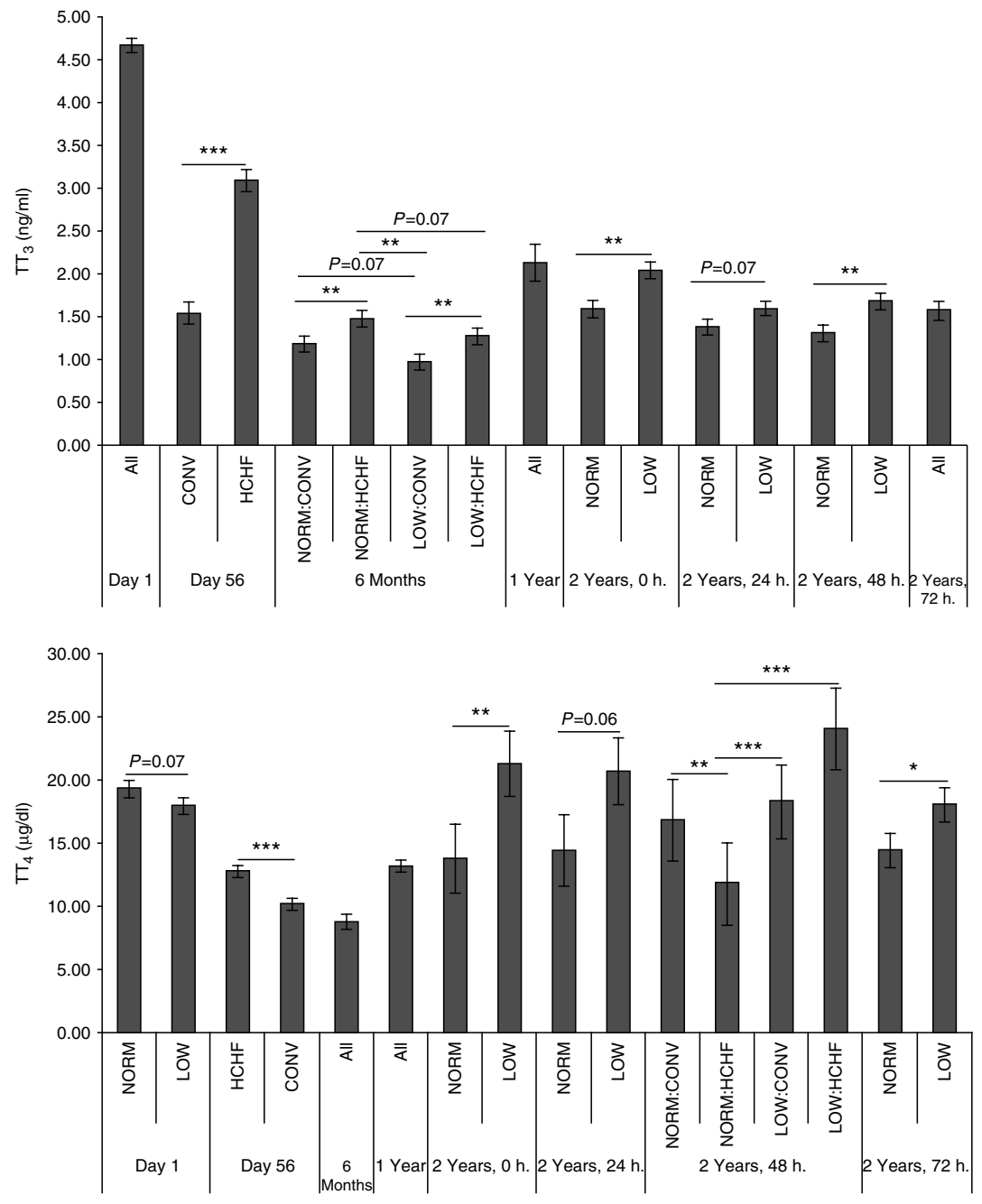

Figure 2

Basal serum concentrations of total $\mathrm{T}_{3}\left(\mathrm{TT}_{3}, \mathrm{ng} / \mathrm{ml}\right)$ and total $\mathrm{T}_{4}\left(\mathrm{TT}_{4}, \mu \mathrm{g} / \mathrm{dl}\right)$ obtained from 1-day, 56-day, 6-month, 1-year, and 2-year-old sheep, as affected by nutrition received during late fetal life and the first 6 months of postnatal life. Samples from 1-day to 6-month-old sheep were obtained from both males and females. All males were killed at 6 months of age, and only female sheep were included in the experiment thereafter. NORM and LOW refer to the plane of nutrition offered to twin-pregnant ewes during late gestation, and CONV and HCHF refer to the postnatal diet fed to either of the twin lambs from day 3 to 6 months of age (see legends to Fig. 1 for further details), thus giving rise to four treatment groups: NORM-CONV, NORM-HCHF, LOW-CONV, and LOW-HCHF. At 2 years of age, time point $0 \mathrm{~h}$ indicates samples taken from the female adult sheep in the fed state, 24- and 48-h samples were obtained after 24 and $48 \mathrm{~h}$ of fasting respectively and 72-h sample was taken $1 \mathrm{~h}$ after re-feeding. All other samples were taken from non-fasted animals. Significant differences are $\star P \leq 0.05, * * P \leq 0.01$, or $* * * P \leq 0.001$. 
age; and differences in the manifested responses with age could be evaluated for the females that were studied until adulthood at 2 years of age.

All statistical models were derived from the same multifactorial model:

$Y_{\mathrm{ijlo}}=\mu+\alpha_{\mathrm{i}}+\alpha \beta_{\mathrm{ij}}+\gamma_{\mathrm{k}}+\alpha \beta \gamma_{\mathrm{ijk}}+\kappa_{\mathrm{l}}+\varepsilon_{\mathrm{ijk}}$

where $Y_{\mathrm{ijlo}}$ is the specific factor, described by all the qualitative explanatory variables, $\mu$ is the overall mean, $\alpha_{\mathrm{i}}$ is the effect of the prenatal NORM or LOW treatment, $\beta_{\mathrm{j}}$ is the effect of the postnatal CONV or HCHF treatment, $\alpha \beta_{\mathrm{ij}}$ is the interaction between the two treatments, $\gamma_{k}$ is the effect of age (or sex; male or female), $\alpha \beta \gamma_{\mathrm{ijk}}$ is the three-way interaction between the two treatments and age (or sex), $\kappa_{1}$ is the random effect of offspring, and $\varepsilon_{\mathrm{ijkl}}$ is the residual variation $\sim n(0, \sigma 2)$. The universal sample space of the qualitative explanatory variables are $i=\{1,2\}, j=\{1,2\}$, $k=\{1,2\}$ (TH's: $k=\{1, \ldots, 5\}$ ), and $l=\{1,2\}$.

All models were tested in R 2.10.1 (R Development Core Team 2010 GNU Project, http://www.r-project.org) using the packages nlme, anova, and lsmeans for fitting, model reductions, and multiple comparisons respectively. Graphic model control (Plot) was carried out to find possible outliers and second, normality assumptions were evaluated by scatterplot, qqnorm, and box-cox. Following this, the model was reduced by testing significance of any interactions by two-way ANOVA. All variables that showed no significance were eliminated from the model in this way. Estimates and significance of the remaining factors were calculated by the function lsmeans in R 2.10.1.

\section{Results}

No effects of prenatal nutrition, postnatal nutrition, or sex were observed unless specifically stated. The basic phenotypic characteristics and performance of the Copenhagen sheep model used in this experiment have been described in detail by Nielsen et al. (2012), but some of the most relevant findings for interpretation of results from this study will be summarized here. When compared with NORM controls, LOW animals exposed to LG-UN had reduced birth weights, had a preference in the very early postnatal period for high-fat dairy cream rather than starch-rich maize, and an increased susceptibility to develop visceral obesity. After conversion to the moderate diet from 6 months to 2 years of age, total body fat content was normalized in the adult HCHF females and became similar to that of CONV sheep, which had been raised on a moderate plane of nutrition throughout the postnatal period.

\section{$\pi_{3}$ and $T_{4}$ in serum}

Prenatal nutrition had no impact on $\mathrm{TT}_{3}$ serum concentrations in the new born lambs (Fig. 2a), whereas $\mathrm{TT}_{4}$ levels tended to be reduced in LOW lambs compared with NORM lambs at day 1 after birth (Fig. 2b). At 56 days of age, the HCHF diet led to significantly higher serum $\mathrm{TT}_{3}$ and $\mathrm{TT}_{4}$ in lambs compared with the CONV lambs at 56 days of age ( $P=0.0002$ and $P=0.0004$ respectively) and at 6 months of age lambs receiving the postnatal $\mathrm{HCHF}$ diet continued to have higher $\mathrm{TT}_{3}$ concentrations compared with their twin on the CONV diet $(P=0.01)$, whereas $\mathrm{TT}_{4}$ concentrations was no longer affected by the postnatal diet at this or older ages. At 1 year of age (where all animals had been fed the same moderate diet for 6 months), postnatal diet effects on $\mathrm{TT}_{3}$ had also disappeared and there were no impacts of prenatal nutrition either. However, in adult females at 2 years of age, an effect of LG-UN became evident, as prenatal LOW sheep had significantly higher levels of both $\mathrm{TT}_{3}$ and $\mathrm{TT}_{4}$ $(P=0.007$ for both) compared with NORM females that had been adequately nourished during late gestation. Furthermore, prenatal LOW sheep continued to have higher concentrations of circulating $\mathrm{TT}_{3}$ and $\mathrm{TT}_{4}$ during a 48-h fasting period. One hour after re-feeding (after

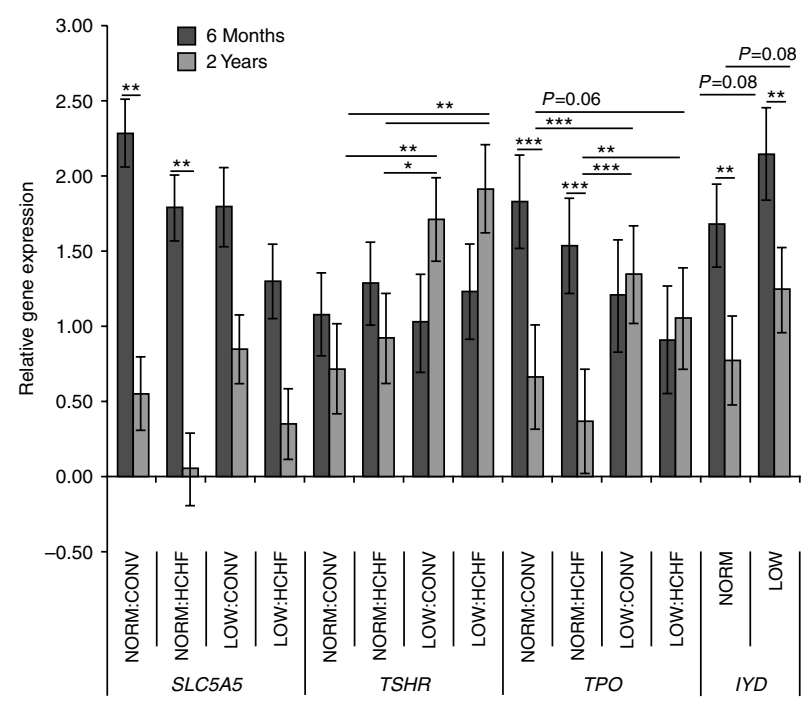

Figure 3

Group means of relative gene expression in the thyroid, for the genes SLC5A5, TSHR, TPO, and IYD from lambs at 6 months (predominantly males) and 2 years (exclusively females) of age, as affected by nutrition received during late fetal life (NORM or LOW) and the first 6 months of postnatal life (CONV or HCHF). The experimental design and dietary treatments have been fully described in legends of Figs 1 and 2 . Significant differences are $* P \leq 0.05, * * P \leq 0.01$, or $* * * P \leq 0.001$.

Published by Bioscientifica Ltd 


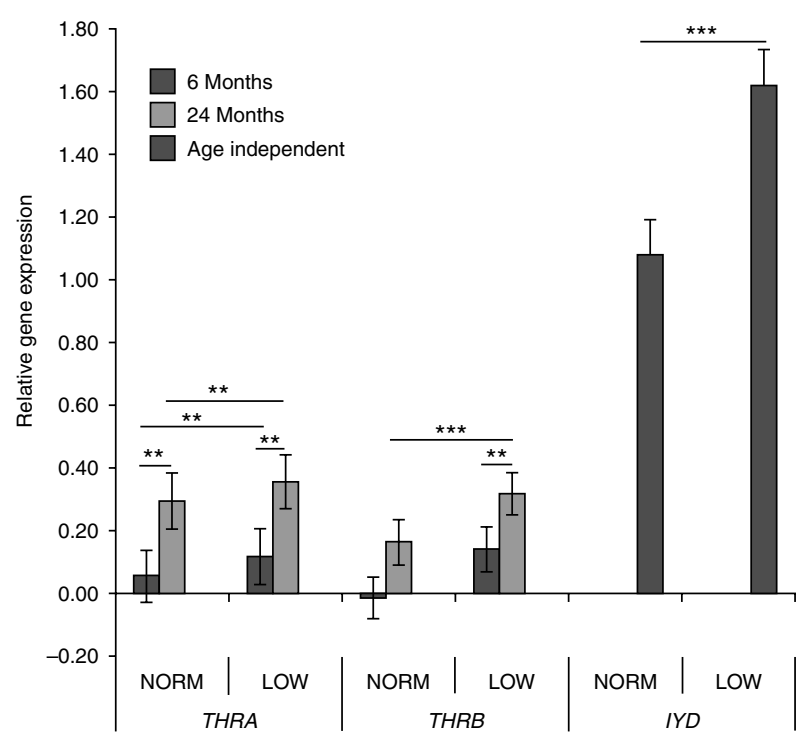

\section{Figure 4}

Group means of relative gene expression in the liver, for the genes THRA, $T H R B$, and IYD from lambs at 6 months (predominantly males) and 2 years (exclusively females) of age, as affected by nutrition received during late fetal life (NORM or LOW) and the first 6 months of postnatal life (CONV or $\mathrm{HCHF}$ ). The experimental design and dietary treatments have been fully described in legends of Figs 1 and 2 . Significant differences are $* * P \leq 0.01$, or $* * * P \leq 0.001$.

3 days of fasting), all animals had equal circulating levels of $\mathrm{TT}_{3}$, but $\mathrm{TT}_{4}$ remained increased in LOW sheep (Fig. 2a and b).

\section{Gene expression in the thyroid gland}

There were no effects of late gestation nutrition on TSHR and TPO expression in 6-month-old predominantly male lambs, but an effect of LG-UN became evident in adulthood, as 2-year-old LOW females had higher TSHR and TPO expression compared with NORM females $(P=0.008-0.05$ and $P=0.0005$ respectively; Fig. 3). IYD expression tended to be significantly upregulated in LOW compared with CONV animals, which was observed in both 6-month-old lambs and 2-year-old sheep.

There were no effects of postnatal diet on expression of any of the abovementioned genes and no effect of neither pre- nor postnatal treatment on DIO2, TG, and SLC5A5 expression in thyroid tissues from 6-month-old lambs or 2-year-old adult sheep. The 2-year-old female sheep generally had lower expression levels of IYD compared with the (mostly male) 6-month-old lambs $(P=0.008)$. In NORM animals, TPO $(P=0.0004)$ and SLC5A5 $(P=0.003)$ was also lower in adult females compared with the predominantly male lambs, but in LOW animals, expression levels of these two genes were similar in lambs and adult sheep.

\section{Gene expression in TH target tissues}

Liver Expression of $\mathrm{DIO} 2$ could not be detected in the liver; therefore, no results are presented for this gene. LOW animals with a history of prenatal undernutrition had higher expression levels compared with NORM animals for THRA $(P=0.008)$ and for IYD $(P=0.0002)$ at both 6 months and 2 years of age and such an effect of prenatal undernutrition also became evident for THRB in adult female sheep at 2 years of age $(P=0.009)$ (Fig. 4). Expression of THRA, THRB, and IYD was generally higher in 2-year-old females compared with 6-month-old (mostly male) lambs. The postnatal diet had no influence on expression of any of these genes in the liver.

Muscle Cardiac Animals subjected to the LOW prenatal treatment had significantly upregulated DIO2, THRA, and THRB expression in cardiac muscle at both 6 months and 2 years of age compared with NORM animals $(P=0.01$, $P=0.0001$, and $P=0.04$ respectively; Fig. 5).

Longissimus dorsi DIO2 was significantly upregulated in longissimus dorsi in the LOW:CONV-fed lambs at 6 months of age compared with all other treatment groups $(P=0.02-0.01)$, but in 2-year-old females, there were no

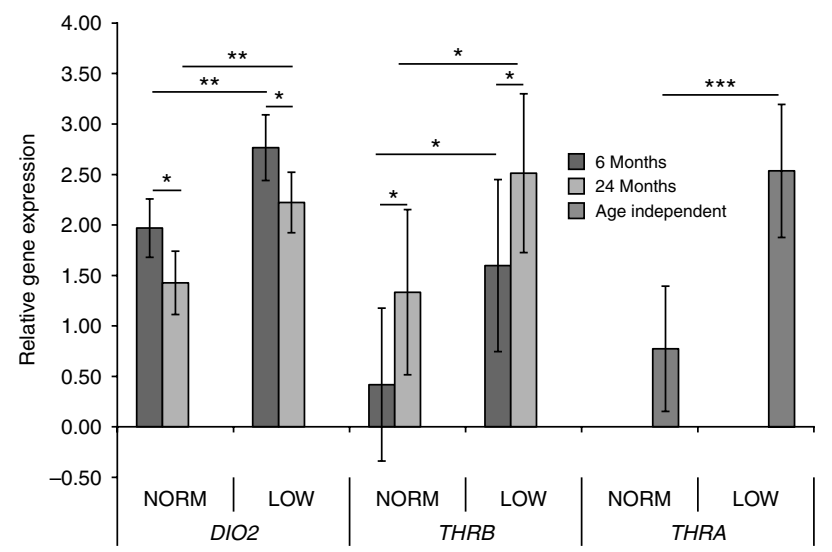

Figure 5

Group means of relative gene expression in cardiac muscle, for the genes THRA, THRB, and DIO2 from lambs at 6 months (predominantly males) and 2 years (exclusively females) of age, as affected by nutrition received during late fetal life (NORM or LOW) and the first 6 months of postnatal life (CONV or HCHF). The experimental design and dietary treatments have been fully described in legends of Figs 1 and 2 . Significant differences are $* P \leq 0.05$, $* * P \leq 0.01$, or $* * * P \leq 0.001$.

Published by Bioscientifica Ltd. 

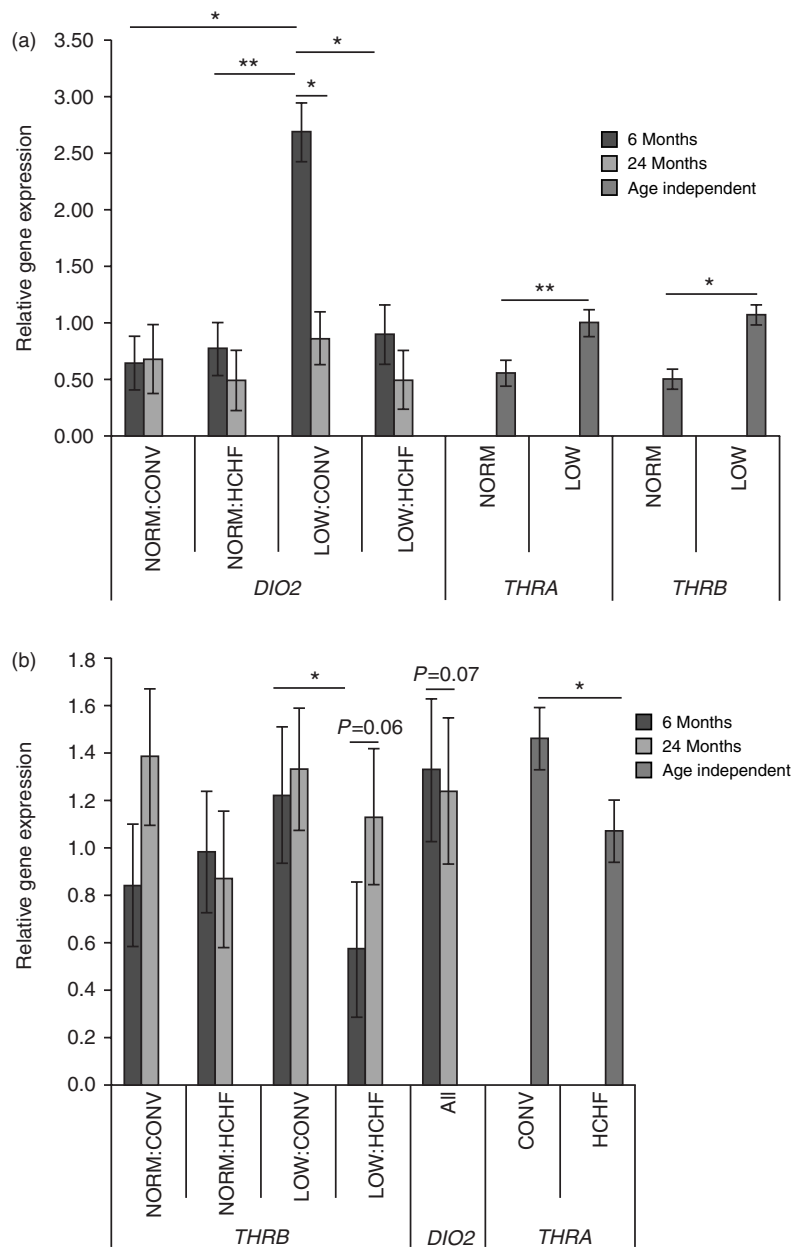

\section{Figure 6}

Group means of relative gene expression in longisimus dorsi (a) and biceps femoris (b) for the genes THRA, THRB, and DIO2 from lambs at 6 months (predominantly males) and 2 years (exclusively females) of age, as affected by nutrition received during late fetal life (NORM or LOW) and the first 6 months of postnatal life (CONV or HCHF). The experimental design and dietary treatments have been fully described in legends of Figs 1 and 2 . Significant differences are ${ }^{*} P \leq 0.05, * * P \leq 0.01$.

differences in DIO2 expression between treatment groups. As for cardiac muscle, both THRA and THRB expression were upregulated in longissimus dorsi in LOW animals compared with NORM animals $(P=0.009$ and $P=0.05$ respectively; Fig. 6a) and in both 6-month-old (mostly male) lambs and in 2-year-old adult female sheep. The postnatal nutrition had no impact on expression patterns of any of these genes in either cardiac or longissimus dorsi muscle.

Biceps femoris This muscle had a different response to early life nutrition exposure compared to cardiac muscle and longissimus dorsi. THRA expression was not affected by prenatal diet in this muscle, but it was significantly downregulated in animals fed the HCHF diet compared with those fed the CONV diet and this was observed not only in 6-month-old lambs, when they were exposed to the different diets, but also in 2-year-old female sheep after they had been fed for $1 \frac{1}{2}$ years on the same moderate diet $(P=0.04)$. The HCHF diet had a similar depressive effect on THRB expression in 6-month-old LOW lambs $(P=0.04)$, but it was not observed in the NORM lambs or in the adult females after diet correction. $\mathrm{DIO} 2$ expression was not affected by neither pre- nor postnatal nutrition but was lower in the 2-year-old females compared with the 6-month-old (mostly male) lambs ( $P=0.07$; Fig. 6b).

Adipose tissue subcutaneous THRA expression in subcutaneous adipose tissue was influenced by the diet received in postnatal life but not by prenatal nutritional history. At 6 months of age, THRA expression was reduced in lambs fed the HCHF diet compared with lambs fed the CONV $\operatorname{diet}(P=0.001-0.01)$. In the adult female sheep, which had been fed $1 \frac{1}{2}$ years on the same moderate diet, there was also an effect of nutrition exposure in early postnatal life on THRA expression, but the effect was opposite to that observed in lambs, as expression levels were highest in the adult sheep that were previously fed the HCHF diet $(P=0.02$; Fig. 7 a). THRB in contrast to THRA was not affected by postnatal nutrition but tended to be affected by prenatal nutrition with LOW having reduced expression levels compared with NORM animals both at 6 months and 2 years of age (Fig. 7a). DIO2 expression was not affected by pre- or postnatal nutritional treatments in animals at any of the two ages.

Visceral THRA expression in visceral adipose tissue was not affected by pre- or postnatal dietary treatments in 6-month-old lambs. But in 2-year-old sheep, expression levels were negatively affected by a history of both LG-UN and EL-ON in an apparently additive way $(P=0.03-0.001)$. In animals that had been adequately nourished as fetuses (NORM), THRA expression levels were higher in the 2-year-old female sheep compared with the 6-month-old (mostly male) lambs $(P=0.005)$. However, in adult sheep with a history of LOW nutrition prenatally, expression levels were substantially depressed relative to 6-month-old lambs (Fig. 7b). THRB expression was not influenced by pre- or postnatal nutritional treatments or age (results not shown). DIO2 expression was significantly reduced in LOW compared with NORM animals that had been fed the CONV diet in postnatal life and this was across both age groups $(P=0.009$; Fig. $7 b)$. This influence of prenatal 

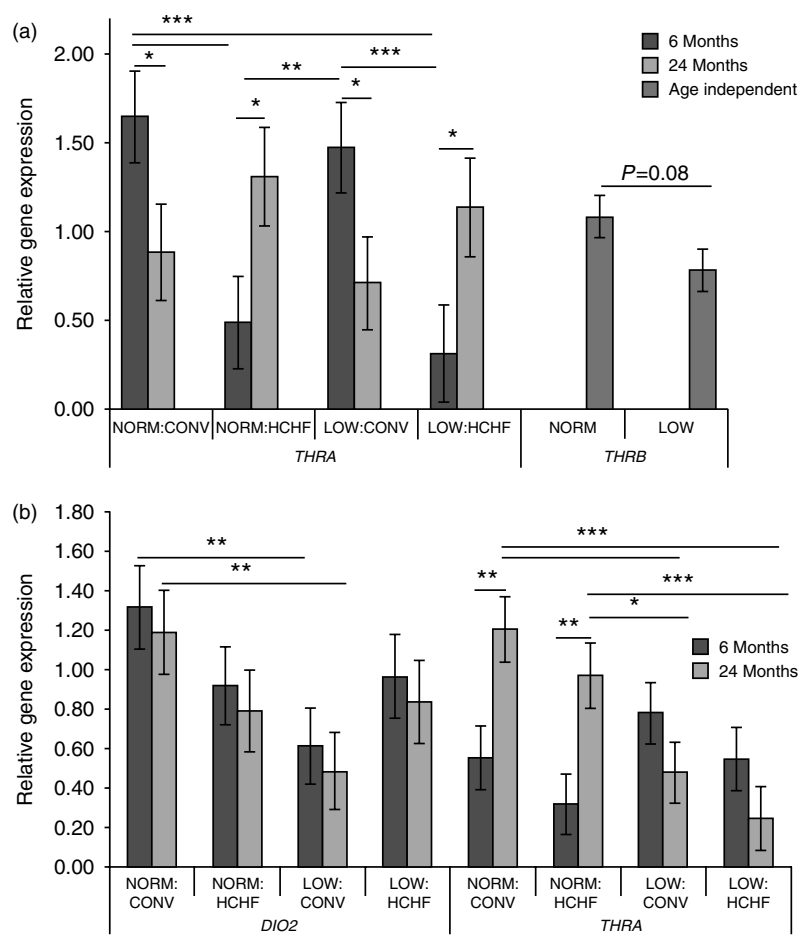

Figure 7

Group means of relative gene expression in subcutaneous adipose tissue (a) and visceral adipose tissue (b), for the genes THRA, THRB, and DIO2 from lambs at 6 months (predominantly males) and 2 years (exclusively females) of age, as affected by nutrition received during late fetal life (NORM or LOW) and the first 6 months of postnatal life (CONV or HCHF). The experimental design and dietary treatments have been fully described in legends of Figs 1 and 2 . Significant differences are $* P \leq 0.05, * * P \leq 0.01$, or $* * * P \leq 0.001$.

nutritional history on $\mathrm{DIO} 2$ expression was not observed in lambs or sheep that were exposed to the HCHF diet in early postnatal life. Expression levels of DIO2 were of similar magnitude in the two age groups.

\section{Discussion}

Fetal origins of health and disease have been quite extensively studied during the last couple of decades (see e.g. review by Correia et al. (2012)), but there is a scarcity of studies focusing on the TH axis. Using our new Copenhagen sheep model (Nielsen et al. 2012), we aimed to study the impacts on $\mathrm{TH}$ axis function and signaling in target tissues of global energy and protein malnutrition during late gestation, combined with different nutrition exposures in the early postnatal period, which included an obesogenic HCHF diet.

Although the experimental design does not allow us to make direct comparisons between sexes with respect to target tissue responses, it was noteworthy that gene expression patterns in 6-month-old male lambs with a history of LG-UN were also quite persistently observed in the 2-year-old adult females subjected to LG-UN. The consistent findings between the LOW male lambs and LOW adult females suggest that the long-term implications of fetal nutrition are hardly restricted to any specific sex.

\section{Effects of LG-UN in growing lambs}

We did not find evidence to suggest that LG-UN significantly affected serum TH levels in female or male lambs, neither at birth nor during the growth period up until puberty. In another sheep study, De Blasio et al. (2006) reported that placental restriction reduced plasma $\mathrm{TT}_{4}$ and increased plasma $\mathrm{TT}_{3}$ in growing lambs. We did see a close-to-significant effect toward $\mathrm{TT}_{4}$ being lowered in 1-day-old LG-UN lambs, but placental restriction (removal of the majority of endometrial caruncles) and global feed restriction may not be directly comparable interventions to induce undernourishment and growth restriction of the fetus. To the best of our knowledge, we are the first to report impacts of nutrition in prenatal life on $\mathrm{TH}$ signaling-related genes in multiple target tissues and we have convincingly demonstrated that the TH axis was indeed a target of programing in response to LG-UN exposure, as distinct changes in gene expression encoding factors involved in $\mathrm{TH}$ signaling in target tissues were observed in the 6-month-old LOW compared with NORM lambs. These effects were manifested irrespectively of which diet the lambs received in early postnatal life, and we found no indications to suggest that the postnatal diet can exacerbate the impacts of a fetal programing of the $\mathrm{TH}$ axis neither in lambs nor in adult sheep. Interestingly, the change in gene expression in response to a history of undernutrition in late fetal life was target tissue specific. Thus, LG-UN-induced upregulation of both deiodinase activity and THRs in metabolically important lean tissues, i.e. liver, cardiac muscle, and longissimus dorsi. This would suggest that the sensitivity toward $\mathrm{TH}$ in these tissues was increased in LOW lambs. However, in adipose tissues, there was a tendency for the opposite response with downregulation of deiodinase and THRs in LOW lambs (see Fig. 8). Based on these results, it is tempting to raise the question whether reduction of the sensitivity in adipose tissue toward catabolic actions of THs is one mechanism whereby LG-UN can increase the predisposition for development of (visceral) obesity later in life? 
Thyroid function in LG-UN adolescent lambs
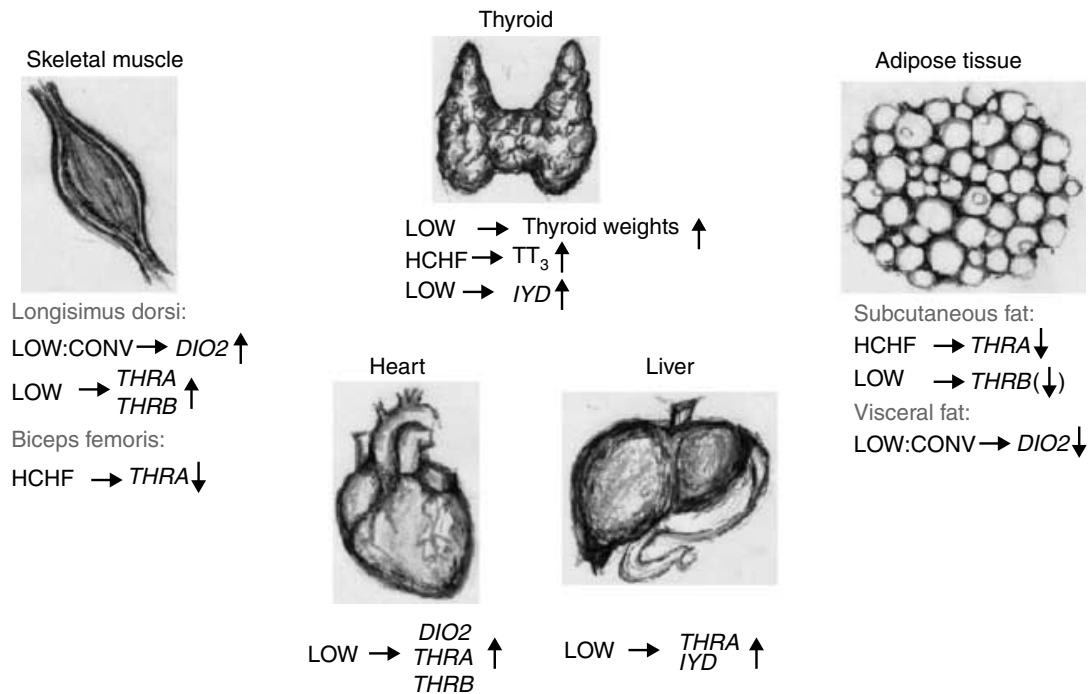

\section{Figure 8}

Overview of the significant alterations mediated by the late gestation undernutrition (LOW) diet or postnatal high-carbohydrate, high-fat (HCHF) diet on thyroid function in adolescent lambs. The experimental design and dietary treatments have been fully described in legends of Figs 1 and 2 . We previously reported that exposure to the prenatal LOW compared with

NORM diet close to significantly increased weight (as a proportion of total body weight) of thyroids in both growing and adult animals ( $P=0.055$; Nielsen et al. 2012). This dietary consequence has therefore been included in the figure. Illustrations by Ms Rikke Lenitha Larsen.

THs have also been shown to stimulate GH/insulinlike growth factor (IGF1) axis signaling and expression of target genes in bone (Yen 2001). Exposure to undernutrition during fetal life results in earlier cessation of growth and a smaller adult body size in sheep (Schinckel \& Short 1961) and humans (Jones 2004), and this was also the tendency in the present experiment (Nielsen et al. 2012). We did not investigate TH signaling in bone tissue in the present experiment, but in a recent sheep study by Lanham et al. (2011), thyroidectomy at 105-110 days of gestation caused fetal growth retardation and the hypothyroid state was associated with significant changes in metatarsal bone structure and strength when analyzed later in gestation (130 and 144 days; term $=147$ days). Future studies are therefore needed to clarify the implications of early programing of TH function also on skeletal development and health later in life.

\section{Effects of LG-UN in adult sheep}

Effects of LG-UN on gene expression patterns in the thyroid and $\mathrm{TH}$ target tissues observed in growing male lambs were also quite consistently observed in adult female sheep (Figs 8 and 9), but in the adult sheep, impacts of LG-UN were also evident for a range of new parameters at both thyroid and target tissue levels (see Fig. 9). Adult females with a history of LG-UN showed signs of hyperthyroidism with increased TH serum level both in the fed and fasted state. Dutra et al. (2003) and Lisboa et al. (2008) have reported similar findings in rats, where nutrient restriction of neonatal rat pups result in hyperthyroid adults. Our adult LOW sheep had upregulated gene expression in the thyroid for the key $\mathrm{TH}$ biosynthesis genes TSHR, IYD, and TPO and upregulated THR expression, THRA and THRB, in heart muscle, liver, and $\mathrm{LD}$, concomitant with increased baseline and fasting serum levels of THs and these findings, along with gross physiological evidence provided in the following, strongly support that these animals were hyperthyroid. The upregulation of THRs THRA and THRB in these major target tissues concomitant with upregulated (cardiac muscle) or unaltered (Biceps Femoris (BF) and Longissimus Dorsi (LD)) expression of $\mathrm{DIO} 2$ indicates that the hyperthyroid state is not induced by peripheral TH resistance. Rather, we speculate that the regulation of thyroid secretion has been programed at a higher level of the Hypothalamic-Pituitary-Thyroidal (HPT) axis, with increased sensitivity toward TSH and TH biosynthesis in the pituitary.

Published by Bioscientifica Ltd. 
Thyroid function in LG-UN young adult sheep
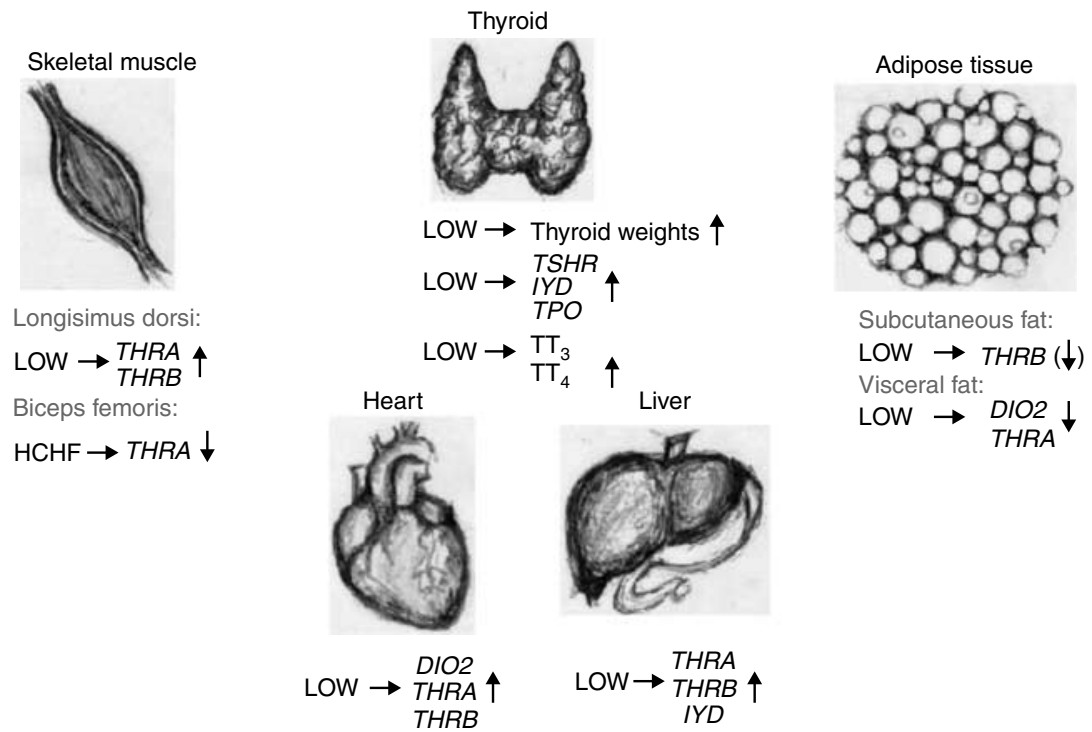

Figure 9

Systemic overview of the significant alterations mediated by the late gestation undernutrition (LOW) diet or postnatal high-carbohydrate, highfat (HCHF) diet on thyroid function in adult sheep. The experimental design and dietary treatments have been fully described in legends to Figs 1 and 2 . We previously reported that exposure to the prenatal LOW compared with

On a gross physiological scale, we know that the transfer of HCHF females to a moderate and body fat correcting diet from 6 months of age resulted in a loss of $\sim 10 \%$ body weight in LOW:HCHF females from 6 to 12 months of age, whereas the NORM-HCHF female sheep maintained their bodyweights during this period (Nielsen et al. 2012). This could reflect an overall higher metabolic rate of the hyperthyroid LG-UN sheep, and indeed Kiani et al. (2008) reported that LG-UN sheep had larger energy expenditures per kilogram Metabolic Body Weight (MBW) compared with sheep that were adequately nourished during fetal life.

That LG-UN programs for hyperthyroidism could offer additional mechanistic explanations to some of the known hallmark symptoms of FMP and associated metabolic disorders later in life, such as fasting hyperglycemia, impaired fasting glucose, impaired glucose tolerance or insulin resistance, systemic inflammation, hypertension, and hyperlipidemia (Fernandez-Twinn \& Ozanne 2010). Hyperthyroidism increases endogenous glucose production, induces hepatic insulin resistance, causes hypertension, and has been associated with low HDL-cholesterol and hyperlipidemia (Cachefo et al. 2001, Biondi et al. 2002, Tancevski et al. 2008, Klieverik
NORM diet close to significantly increased weight (as a proportion of total body weight) of thyroids in both growing and adult animals ( $P=0.055$; Nielsen et al. 2012). This dietary consequence has therefore been included in the figure. Illustrations by Ms Rikke Lenitha Larsen.

et al. 2009). Indeed, we found that LG-UN female sheep at 2 years of age cleared insulin significantly slower during insulin challenge than NORM females (Kongsted 2011). Another hallmark symptom of FMP is obesity. Hyperthyroidism would normally be associated with loss of body weight, but interestingly in this study, we found that THRA, THRB, and/or DIO2 were downregulated in adipose tissue, opposite to the upregulation observed in other target tissues, and we hypothesize that this can impair the potential catabolic actions of THs in adipose tissue in LG-UN individuals and thereby increase their susceptibility for development of obesity when nutrition is abundant.

\section{Effect of early life overnutrition in growing lambs}

Male and female lambs fed the obesogenic HCHF diet had, as expected, significantly higher serum $\mathrm{TT}_{3}$ levels compared with their twin lambs fed the moderate CONV diet during the time they were exposed to this diet (Fig. 8). It is well documented that accumulation of body fat is positively correlated with adipose leptin synthesis and leptin concentration in plasma and leptin can, in turn

Published by Bioscientifica Ltd 
upon binding to specific receptors in the arcuate nucleus of the hypothalamus, induce neuroendocrine changes resulting in increased release of TRH from the hypothalamus, TSH from the pituitary gland, and thereby TH from the thyroid glands (Costa da Veiga et al. 2004).

There were remarkably few effects of the extreme (for a ruminant animal) HCHF diet on expression of genes encoding for factors involved in $\mathrm{TH}$ signaling in target tissues. In fact, only two significant results were found and both regarded THRA, which was downregulated in both BF muscle and subcutaneous adipose tissue. The different responses in muscles to pre- and postnatal dietary exposure could not be related to whether the muscles contained predominantly glycolytic (LD) or oxidative (cardiac and BF) muscle fibers (Jørgensen et al. 2009).

\section{Effect of early life overnutrition in adult sheep}

The increased $\mathrm{TH}$ concentrations observed in the 6-month-old male and female HCHF fed lambs were clearly related directly to the dietary intake at that time, as there were no indications of any postnatal dietary impacts on serum TH levels in the same females after they had been fed a moderate (and body fat correcting) diet for 6 months or more. This is in line with the results from Sari et al. (2003), who found that weight loss in women could restore TSH levels to normal.

LG-UN resulted in upregulated gene expression in LD and cardiac muscle regardless of age, whereas only one long-term implication of EL-ON could be detected, and it was downregulation of THRA expression in BF, as also observed in the male lambs at 6 months of age. It could be speculated that the HCHF diet-reduced expression of THRA in BF facilitates an increased capacity for triglyceride uptake and/or accumulation in this predominantly oxidative muscle. Thus, the observed differentiated effects of LG-UN and EL-ON on TH signaling in the different muscles suggest that quite specific long-term metabolic adaptation can be induced in different tissues depending on the nutritional environment in particularly pre- but also postnatal life.

In conclusion, LG-UN unmistakably programed the TH axis resulting in adult hyperthyroidism associated with increased thyroid expression of genes regulating $\mathrm{TH}$ synthesis and deiodination and increased THR and deiodinase expression in one or more of the target tissues liver, cardiac muscle, and longissimus dorsi muscle but decreased THR and deiodinase expression in adipose tissues. LG-UN thus appears to program for differentiated $\mathrm{TH}$ response or sensitivity in major target tissues. The programing effects mediated by LG-UN on TH signaling in target tissues were evident early in life, before LG-UN effects could be detected in circulating levels of $\mathrm{TT}_{3}$ and $\mathrm{TT}_{4}$ in serum. LG-UN effects were permanent and became even more strongly expressed in adulthood. Further studies are required to establish whether the apparently differential TH signaling in adipose vs other tissues can be part of a mechanism linking LG-UN to altered growth trajectories and increased predisposition for visceral obesity and associated disorders. Early postnatal dietary treatment effects on $\mathrm{TH}$ axis parameters were in general remarkably few and reversible and had no impact on the expression of fetal programing of the $\mathrm{TH}$ axis function. This suggests that the time-of-birth is a critical set point for when long-term programing of $\mathrm{TH}$ axis function can occur and this should be considered in the choice of experimental animal models when late gestation impacts are in focus.

\section{Declaration of interest}

The authors declare that there is no conflict of interest that could be perceived as prejudicing the impartiality of the research reported.

\section{Funding}

This study was part of the research program of the Centre for Fetal Programming (CFP) and supported by the Danish Council for Strategic Research (grants 09-059921 and 09-067124).

\section{Author contribution statement}

PhD Fellow $L J$ has been in charge of all the laboratory procedures, statistical evaluation of data, and for writing the manuscript. Post doc $\mathrm{A} \mathrm{H}$ $K$ has contributed with valuable inputs in the interpretation of results and manuscript revision. Associate Prof. $\mathrm{M} O \mathrm{~N}$, vice-director of the Danish Centre for Fetal Programming, was the overall responsible person for designing the experiment and developing the experimental sheep model, for evaluating the results, and finalizing the manuscript. All three authors were actively involved in the underlying experimental animal work.

\section{Acknowledgements}

The authors would like to thank Ms R L Larsen for the anatomical illustrations made for this article and Associate Prof. AT Jensen for support in statistical computations. The authors would also like to acknowledge Ms V G Christensen, Mr D S Jensen, Ms R Jensen, Ms M L Hansen, Mr A Ali, Ms M Stubgaard, and Ms L E Carlsen for their valuable technical assistance. They also wish to express their gratitude to the following people for expert help with handling of experimental animal, killing, and samplings: the experimental farm staff at the Faculty of Health and Medical Sciences, University of Copenhagen, Denmark, PhD students Mr A Kiani and Ms A N Rasmussen, animal science students Ms A C F Støy, Ms M B Petersen, Ms H F Hedegaard, Ms M Kjaergaard, Ms K F Dahlbach, Mr M P Jensen, Ms B C Jensen, and Ms S R Thomasen.

Published by Bioscientifica Ltd 


\section{References}

Amuna P \& Zotor FB 2008 The epidemiological and nutrition transition in developing countries: evolving trends and their impact in public health and human development. Proceedings of the Nutrition Society 67 82-90. (doi:10.1017/S0029665108006058)

Ayturk S, Gursoy A, Kut A, Anil C, Nar A \& Tutuncu NB 2009 Metabolic syndrome and its components are associated with increased thyroid volume and nodule prevalence in a mild-to-moderate iodine-deficient area. European Journal of Endocrinology 161 599-605. (doi:10.1530/ EJE-09-0410)

Biondi B, Palmieri EA, Lombardi G \& Fazio S 2002 Effects of thyroid hormone on cardiac function: the relative importance of heart rate, loading conditions, and myocardial contractility in the regulation of cardiac performance in human hyperthyroidism. Journal of Clinical Endocrinology and Metabolism 87 968-974. (doi:10.1210/jc.87.3.968)

Bloomfield FH, Oliver MH, Hawkins P, Holloway AC, Campbell M, Gluckman PD, Harding JE \& Challis JRG 2004 Periconceptional undernutrition in sheep accelerates maturation of the fetal hypothalamic-pituitary-adrenal axis in late gestation. Endocrinology 145 4278-4285. (doi:10.1210/en.2004-0424)

Bocian-Sobkowska J, Wozniak W \& Malendowicz LK 1997 Morphometric studies on the development of the human thyroid gland. II. The late fetal life. Histology and Histopathology 12 79-84.

Bol VV, Delattre A-I, Reusens B, Raes M \& Remacle C 2009 Forced catch-up growth after fetal protein restriction alters the adipose tissue gene expression program leading to obesity in adult mice. American Journal of Physiology. Regulatory, Integrative and Comparative Physiology 297 291-299. (doi:10.1152/ajpregu.90497.2008)

Bonomo IT, Lisboa PC, Passos MCF, Alves BA, Reis AM \& de Moura EG 2008 Prolactin inhibition at the end of lactation programs for hypothyroidism in adult rat. Journal of Endocrinology 198 331-337. (doi:10.1677/ JOE-07-0505)

Brix TH, Kyvik KO \& Hegedüs L 2000 Low birth weight is not associated with clinically overt thyroid disease: a population based twin case-control study. Clinical Endocrinology 53 171-176. (doi:10.1046/ j.1365-2265.2000.01025.x)

Cachefo A, Boucher P, Vidon C, Dusserre E, Diraison F \& Beylot M 2001 Hepatic lipogenesis and cholesterol synthesis in hyperthyroid patients. Journal of Clinical Endocrinology and Metabolism 86 5353-5357. (doi:10.1210/jc.86.11.5353)

Correia MLG, Volpato AM, Águila MB \& Mandarim-de-Lacerda CA 2012 Developmental origins of health and disease: experimental and human evidence of fetal programming for metabolic syndrome. Journal of Human Hypertension 26 405-419. (doi:10.1038/jhh.2011.61)

Costa da Veiga MAL, de Jesus Oliveira K, Curty FH \& Pazos de Moura CC 2004 Thyroid hormones modulate the endocrine and autocrine/paracrine actions of leptin on thyrotropin secretion. Journal of Endocrinology 183 243-247. (doi:10.1677/joe.1.05746)

De Blasio MJ, Gatford KL, Robinson JS \& Owens JA 2006 Placental restriction alters circulating thyroid hormone in the young lamb postnatally. American Journal of Physiology Regulatory, Integrative and Comparative Physiology 291 1016-1024.

Dussault JH \& Labrie F 1975 Development of the hypothalamic-pituitarythyroid axis in the neonatal rat. Endocrinology 97 1321-1324. (doi:10.1210/endo-97-5-1321)

Dutra SCP, Passos MCF, Lisboa PC, Santos RS, Cabanelas AP, Pazos-Moura CC \& Moura EG 2003 Liver deiodinase activity is increased in adult rats whose mothers were submitted to malnutrition during lactation. Hormone and Metabolic Research 35 268-270. (doi:10.1055/s-200339485)

Fernandez-Twinn DS \& Ozanne SE 2010 Early life nutrition and metabolic programming. Annals of the New York Academy of Sciences 1212 78-96. (doi:10.1111/j.1749-6632.2010.05798.x)
Hájovská K 2002 Prenatal thyroid gland in sheep with regard to the presence of isthmus. Anatomia, Histologia, Embryologia 31 300-302. (doi:10.1046/j.1439-0264.2002.00402.x)

Husted SM, Nielsen MO, Tygesen MP, Kiani A, Blache D \& Ingvartsen KL 2008 Programming of intermediate metabolism in young lambs affected by late gestational maternal undernourishment. American Journal of Physiology. Endocrinology and Metabolism 293 E548-E557. (doi:10.1152/ajpendo.00441.2006)

Jones JH 2004 Fetal programming: adaptive life-history tactics or making the best of a bad start? American Journal of Human Biology 17 22-23. (doi:10.1002/ajhb.20099)

Jørgensen W, Gam C, Andersen JL, Schjerling P, Scheibye-Knudsen M, Mortensen OH, Grunnet N, Nielsen MO \& Quistorff B 2009 Changed mitochondrial function by pre- and/or postpartum diet alterations in sheep. American Journal of Physiology. Endocrinology and Metabolism 297 1349-1357. (doi:10.1152/ajpendo.00505.2009)

Kajantie E, Phillips DIW, Osmond C, Barker DJP, Forsén T \& Eriksson JG 2006 Spontaneous hypothyroidism in adult women is predicted by small body size at birth and during childhood. Journal of Clinical Endocrinology and Metabolism 91 4953-4956. (doi:10.1210/ jc.2006-1093)

Kiani A, Chwalibog A, Tygesen MP \& Nielsen MO 2008 Effect of undernutrition in foetal life on energy expenditure during gestation in ewes. Archives of Animal Nutrition 62 117-126. (doi:10.1080/ 17450390801892542)

Klieverik LP, Janssen SF, van Riel A, Foppen E, Bisschop PH, Serlie MJ, Boelen A, Ackermans MT, Sauerwein HP, Fliers E et al. 2009 Thyroid hormone modulates glucose production via a sympathetic pathway from the hypothalamic paraventricular nucleus to the liver. PNAS 106 5966-5971. (doi:10.1073/pnas.0805355106)

Kongsted AH 2011 Late gestation nutrient restriction and postnatal high carbohydrate and high fat feeding may predispose for the metabolic syndrome at an early age - evidence from a sheep model. PhD Thesis (ISBN 978-87-7611-488-6).

Kratzsch J \& Pulzer F 2008 Thyroid gland development and defects. Best Practice \& Research. Clinical Endocrinology \& Metabolism 22 55-75. (doi:10.1016/j.beem.2007.08.006)

Laitinen J, Pietiläinen K, Wadsworth M, Sovio U \& Järvelin M-R 2004 Predictors of abdominal obesity among 31-y-old men and women born in Northern Finland in 1966. European Journal of Clinical Nutrition $\mathbf{5 8}$ 180-190.

Lanham SA, Fowden AL, Roberts C, Cooper C, Oreffo RO \& Forhead AJ 2011 Effects of hypothyroidism on the structure and mechanical properties of bone in the ovine fetus. Journal of Endocrinology 11 189-198. (doi:10.1530/JOE-11-0138)

Limesand SW, Rozance PJ, Zerbe GO, Hutton JC \& Hay WW Jr 2006 Attenuated insulin release and storage in fetal sheep pancreatic islets with intrauterine growth restriction. Endocrinology 147 1488-1497. (doi:10.1210/en.2005-0900)

Lisboa PC, Fagundes ATS, Denolato ATA, Oliveira E, Bonomo IT, Alves SB, Curty FH, Passos MCF \& Moura EG 2008 Neonatal low-protein diet changes deiodinase activities and pituitary TSH response to TRH in adult rats. Experimental Biology and Medicine 233 57-63. (doi:10.3181/ 0705-RM-146)

Lisboa PC, Pires L, de Oliveira E, Lima NS, Bonomo IT, Reis AM, Passos MCF \& Moura EG 2010 Prolactin inhibition at mid-lactation influences adiposity and thyroid function in adult rats. Hormone and Metabolic Research 42 562-569. (doi:10.1055/s-0030-1253434)

Nielsen MO, Kongsted AH, Thygesen MP, Strathe AB, Caddy S, Quistorff B, Jørgensen W, Christensen VG, Husted S, Chwalibog A et al. 2013 Visceral adiposity and preference for a high-fat diet are affected by late gestation undernutrition in sheep and exacerbated by a high-fat diet in early life. British Journal of Nutrition. In Press. (doi:10.1017/S000 7114512004199)

Ozanne SE, Olsen GS, Hansen LL, Tingey KJ, Nave BT, Wang CL, Hartil K, Petry CJ, Buckley AJ \& Mosthaf-Seedorf L 2003 Early growth restriction 
leads to down regulation of protein kinase $\mathrm{C}$ zeta and insulin resistance in skeletal muscle. Journal of Endocrinology 177 235-241. (doi:10.1677/ joe.0.1770235)

Ozanne SE, Jensen CB, Tingey KJ, Storgaard H, Madsbad S \& Vaag AA 2005 Low birthweight is associated with specific changes in muscle insulinsignalling protein expression. Diabetologia 48 547-552. (doi:10.1007/ s00125-005-1669-7)

Pergola GD, Giorgino F, Benigno R, Guida P \& Giorgino R 2008 Independent influence of insulin, catecholamines, and thyroid hormones on metabolic syndrome. Obesity 16 2405-2411. (doi:10.1038/oby.2008.382)

Phillips DIW, Barker DJP, Fall CHD, Seckl JR, Whorwood CB, Wood PJ \& Walker BR 1998 Elevated plasma cortisol concentrations: a link between low birth weight and the insulin resistance syndrome. Journal of Clinical Endocrinology and Metabolism 83 757-760. (doi:10.1210/jc.83.3.757)

Rae MT, Rhind SM, Kyle CE, Miller DW \& Brooks AN 2002 Maternal undernutrition alters triiodothyronine concentrations and pituitary response to GnRH in fetal sheep. Journal of Endocrinology 173 449-455. (doi:10.1677/joe.0.1730449)

Rezzonico J, Rezzonico M, Pusiol E, Pitoia F \& Niepomniszcze H 2008 Introducing the thyroid gland as another victim of the insulin resistance syndrome. Thyroid 18 461-464. (doi:10.1089/thy.2007.0223)
Rich-Edwards JW, Kleinman K, Michels KB, Stampfer MJ, Manson JE, Rexrode KM, Hibert EN \& Willet WC 2005 Longitudinal study of birth weight and adult body mass index in predicting risk of coronary heart disease and stroke in women. BMJ 330 1115. 1-6. (doi:10.1136/bmj. 38434.629630.E0)

Sari R, Balci MK, Altunbas H \& Karayalcin U 2003 The effect of body weight and weight loss on thyroid volume in obese women. Clinical Endocrinology 59 258-262. (doi:10.1046/j.1365-2265.2003.01836.x)

Schinckel PG \& Short BF 1961 The influence of nutritional level during pre-natal and early post-natal life on adult fleece and body characters. Australian Journal of Agricultural Research 12 176-202. (doi:10.1071/ AR9610176)

Tancevski I, Wehinger A, Demetz E, Eller P, Duwensee K, Huber J, Hochegger K, Schgoer W, Fievet C, Stellaard F et al. 2008 Reduced plasma high-density lipoprotein cholesterol in hyperthyroid mice coincides with decreased hepatic adenosine $5^{\prime}$-triphosphate-binding cassette transporter 1 expression. Endocrinology 149 3708-3712. (doi:10.1210/en.2007-1387)

Woodall SM, Johnston BM, Breier BH \& Gluckman PD 1996 Chronic maternal undernutrition in the rat leads to delayed postnatal growth and elevated blood pressure of offspring. Pediatric Research 40 438-443. (doi:10.1203/00006450-199609000-00012)

Yen PM 2001 Physiological and molecular basis of thyroid hormone action. Physiological Reviews 81 1097-1142.

Received in final form 3 December 2012

Accepted 3 January 2013

Accepted Preprint published online 3 January 2013
(C) 2013 Society for Endocrinology Printed in Great Britain 